\title{
Disaster Risks and Community Response: A Case Study from Ilam, Nepal ${ }^{\dagger}$
}

\author{
Pratima Poudel \\ Himalayan College of Agricultural Sciences and Technology (HICAST), Purbanchal University, Pushpalal \\ Chowk, Biratnagar 56600, Nepal; poudelprati@gmail.com \\ + Presented at the 1st International Electronic Conference on Environmental Health Sciences, \\ 15 November-7 December 2018; Available online: https://iecehs-1.sciforum.net/. \\ Published: 14 November 2018
}

\begin{abstract}
A field study was conducted in six Village Development Committees (VDCs) of Ilam district to identify common disasters linked with climate change and people's response mechanisms to those disasters in farming communities. Altogether, 300 randomly selected households facing different disaster problems were interviewed using a structured and semi-structured questionnaire, which was supplemented by direct observation, timeline analysis, a key informant interview, and a focus group discussion. In addition, secondary data were collected from the District Agriculture Development Office (DADO), Ilam, the Central Bureau of Statistics (CBS) and the Nepal Red Cross Society (NRCS), Ilam. Farmers' perceptions and the reviewed literature revealed that floods, landslides, droughts, insect pests, hailstorms, and fires comprise a major disaster risk, and they have been affecting agriculture, livelihood, physical infrastructure, and property for years. It was found that different types of loss, such as landslides, have the following risks and impacts: loss of land (45\% of families) and crops (90\%), property loss (10\%), loss of physical resources (50\%), effects on water resources $(69 \%)$, loss of livestock (5\%), forest degradation $(72 \%)$ and loss of human life (3\%). The risks and impacts of flood, drought, and fire are also presented in this study. It was also found that local communities adopt different mitigation measures for different disasters including afforestation, checking dam construction, awareness creation, contour farming, relocation, shed reconstruction, construction of plastic ponds, and conservation of local varieties (different frequencies for different measures). Social networks play an important role in mitigating disaster risks. People get help from government ( $38 \%$ families) and non-government ( $50 \%$ families) organizations, friends (22\%), neighbors $(44 \%)$ and relatives $(20 \%)$ in the form of loans $(18 \%)$, helping hands or physical support (77\%), information $(62 \%)$, and basic need materials $(48 \%)$ to manage or respond to disaster risks. The paper suggests that local mitigation measures need to be supplemented by more sustainable solutions to make the efforts sustainable, which requires local level integrated planning and coordinated efforts.
\end{abstract}

Keywords: disaster risk reduction; agriculture; livelihood resources; adaptation; sustainable development

\section{Introduction}

Nepal is prone to a variety of recurring natural disasters, such as floods, landslides, snow avalanches, glacial lake outburst floods (GLOF), hailstorms, thunderstorms, cold waves, hot waves, droughts, epidemics, and earthquakes. Out of the 75 districts in the country, 49 are prone to floods and/or landslides, 23 to wildfires, and one to windstorms. A total of 64 out of 75 districts are prone to disasters of some type [1]. Natural disasters include earthquakes, fires, floods, landslides, heavy rains, droughts, famine, epidemics, and other similar natural disasters [2,3]. They include industrial 
accidents or accidents caused by explosions or poisoning and any other kinds of disasters [4]. According to the Action Aid Position Paper, any situation where there is an exceptional and widespread threat to life and the subsistence that is beyond the coping capacity of individuals and/or the community is to be considered an emergency and disaster. There is a significant convergence between the problems that disaster risk reduction and climate change adaptation seek to address [5].

As shown in Figure 1, populations already exposed to climate-related hazards and effects will be at greater risk due to a projected increase in the frequency and/or the intensity of those hazards and effects as a result of global climate change.

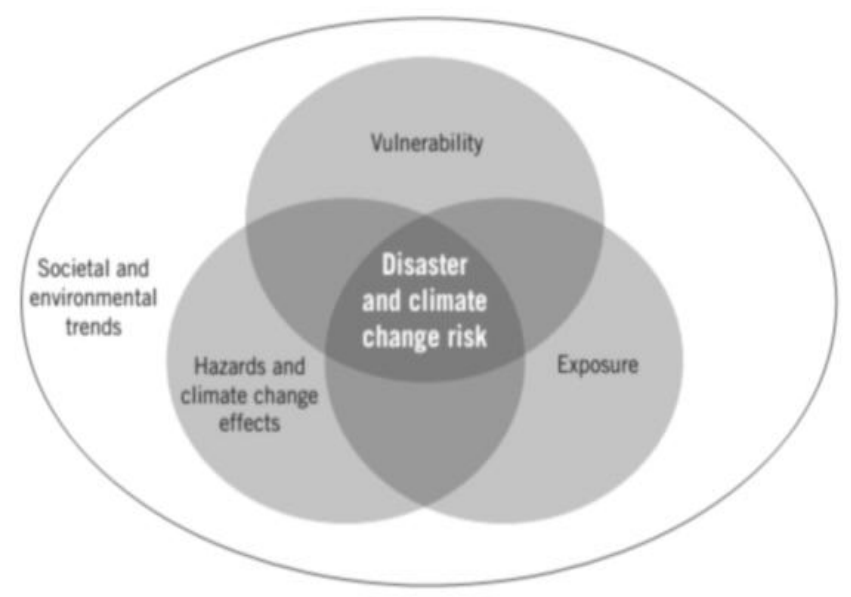

Figure 1. Disaster and climate change risk [4].

Furthermore, populations exposed to hazards may experience stresses due to longer-term changes in the climate-such as changes in seasonality, unpredictable rainfall, and sea-level risethat affect their livelihoods and health, making them more vulnerable to all types of shocks, events and further changes. Disaster risk reduction and climate change adaptation also share a common conceptual understanding of the components of risk and the processes of building resilience. The two approaches regard risk as the product of exposure and vulnerability, either to hazard(s) or the effect(s) of climate change, or both. The greater the vulnerability, exposure, and magnitude or likelihood of the hazard/climate change effect, the greater the risk. Both exposure and vulnerability are compounded by other societal and environmental trends, e.g., urbanization, environmental degradation, and the globalization of markets $[6,7]$. Thus, to reduce disaster and climate change risk, exposure needs to be minimized, vulnerability reduced, and capacities for resilience strengthened in ways that address both disaster and climate change risk simultaneously, with neither approach compromising the other $[8,9]$.

This study identified the major disasters occurring in the Ilam district, as well as documenting the indigenous knowledge of the community regarding disaster risks and response.

\section{Materials and Methods}

Farmers residing around Ilam Municipality and the associated disaster-prone area were the target population for the study. In particular, the study targeted residents of the six Village Development Committe's of Ilam District, Nepal, i.e., Kanyam, Chulachuli, Bhanjyang, Godhak, Namsaling and, Sangrumba. Altogether, 300 respondents were selected by applying a simple random sampling method with multiple responses.

Both primary and secondary data were collected and analyzed. Primary data were collected by using different participatory rural appraisal tools, such as focus group discussions, key informant interviews, transect walks, timelines, and community consultation. Furthermore, a household survey using structured and semi-structured questionnaires helped to gather detailed information, with 50 farmers over 30 years of age from each village were the main respondents, each with 10 years of experience facing these natural hazards. The study was based on the farmers' perceptions, the effects 
of disasters and the methods they applied to cope with the situation. The secondary information was collected from various publications, such as journals, research articles, proceedings of various nongovernmental organizations (NGOs) and international non-governmental organizations (INGOs), reports of the District Agriculture Development Office (DADO), the District Development Committee (DDC), the Nepal Agricultural Research Council (NARC), the Central Bureau of Statistics (CBS), the Ministry of Agriculture and Cooperatives, and the Department of Hydrology and Meteorology. Data analysis was carried out using SPSS and MS Excel.

\section{Results and Discussion}

\subsection{Change in the Climatic Conditions}

The increasing trend of rising temperatures and precipitation extremes has been observed in Nepal along with incidences of heavy precipitation that, in many cases, ultimately lead to disasters. Compared to the past 10-15 years, the climatic conditions have changed. Summer temperatures are getting hotter and the period of the summer season has also increased accordingly. Almost all respondents felt that it has become more difficult for them to tolerate solar radiation nowadays than in the previous 10-15 years. Also, the level of rainfall, drought, fog and hailstorms has either increased or decreased.

Regarding the winter temperatures, respondents said that the winters have become colder, while some claimed that winters have become milder. Fifteen years ago, the winter season started in October and remained until March. However, nowadays, the winter period has shortened from November to January. As shown in Table 1, based on the responses of the respondents, it can be said that in their perception climate extremes have increased, as $99 \%$ of respondents claimed that the weather is changing. However, according to available data on temperature from the Ilam and Kanyam weather stations, there has been very little change in the average annual temperatures (both maximum and minimum) and the information on rainfall is inconsistent between stations.

Table 1. Change in the climatic conditions of Ilam, Nepal, 2013.

\begin{tabular}{cc}
\hline Climate Changes & Percent (Multiple Response) \\
\hline Change in weather & 99 \\
Increase in temperature & 92.3 \\
Change in rainfall pattern & 88 \\
Change in windstorm & 65.3 \\
Change in pattern of drought & 56 \\
Decrease in hailstorm & 53.7 \\
Decreasing erratic rainfall & 48.7 \\
Increasing erratic rainfall & 31 \\
Change in pattern of hailstorm & 29.3 \\
Decrease in fog & 28 \\
Increase in fog & 23.7 \\
Increase in hailstorm & 12.3 \\
Decrease in temperature & 9.3 \\
\hline
\end{tabular}

\subsection{Major Climatic Hazards}

Different past major climatic hazards were analyzed using a timeline, as it is shown in Table 2. Those hazards were investigated through group discussions with villagers before being gathered and presented on the timeline below: 
Table 2. Timeline of the climatic hazards (according to the Nepalese solar system calendar bikram sambat).

\begin{tabular}{|c|c|c|}
\hline Place & Event & Consequences \\
\hline Godhak & $\begin{array}{l}\text { Landslides (2045) } \\
\text { Flood }(2030,2045 \\
\quad 2053,2064) \\
\text { Drought }(2034- \\
\quad 2035) \\
\text { Hail (2030 and } \\
\text { 2064-2065) } \\
\text { Insects (2052-2053) } \\
\text { Snowfall (2002) }\end{array}$ & $\begin{array}{c}12 \text { households washed away } \\
\text { Loss of cardamom fields } \\
\text { Drought effects on maize } \\
\text { No cardamom production for } 3 \text { years } \\
\text { Death of fish } \\
\text { Problems with rhizome rot, whitefly } \\
\text { Extinction of buckwheat, horse gram, and mustard } \\
\text { Replacement of local cow breed Jure with Holstein and Jersey } \\
\text { Arrival of new varieties i.e., tomato, cow, pea, squash and pumpkin } \\
\text { Extinction of jackal, porcupine, rupi, and crow, and increase of rabbit } \\
\text { and monkey } \\
\text { Increase of Variegata acranthus } \\
10-15 \text { years ago, there was a problem with the dew }\end{array}$ \\
\hline Kanyam & $\begin{array}{l}\text { Flood }(2090,2011 \\
\text { 2025, 2069) } \\
\text { Drought }(2028) \\
\text { Insects } \\
\text { Hail } \\
\text { Snowfall (2028, } \\
\text { 2033-2034) } \\
\text { Hurricane (2066) } \\
\text { Dew (2068-2069) }\end{array}$ & $\begin{array}{c}\text { Loss of human life and livestock } \\
4 \text { households migrated } \\
\text { Minibus carrying } 14 \text { people washed away } \\
\text { Cardamom and broom grassland washed away } \\
\text { No production of maize } \\
\text { Replacement of indigenous crops with hybrid varieties } \\
\text { Extinction of fox and jackal in the past } 15 \text { years and an increase in rabbit } \\
\text { Problems with aphid and mosquito for } 2 \text { years } \\
\text { Rhizome rot } \\
\text { Destruction of leaches } \\
1 \text { death due to hurricane }\end{array}$ \\
\hline Bhanjyang & $\begin{array}{l}\text { Landslides } \\
\text { Heavy rainfall } \\
\text { Hail } \\
\text { Drought } \\
\text { Frost } \\
\text { Outbreaks of new } \\
\text { diseases }\end{array}$ & $\begin{array}{l}\text { Landslides occurred } 45 \text { years ago, which killed seven people and } \\
\text { washed away Nigure village } \\
\text { People recall that the raindrops were so large that they made holes in } \\
\text { roads and several other places. The rainfall was unexpected and } \\
\text { strange, and occurred only over an area about } 50 \text { meters in diameter } \\
\text { 12-13 years ago, in the month of Mangsir (November-December), hail } \\
\text { shattered rice crops, causing more than } 80 \% \text { crop loss. The normal } \\
\text { period for hail is Chaitra (March)-Baisakh (April) } \\
\text { Liver fluke did not exist in the past, but now it has become a very } \\
\text { common and sudden cause of death in healthy-looking goats }\end{array}$ \\
\hline Chulachuli & $\begin{array}{l}\text { Flood (2036, 2048, } \\
\text { 2070) } \\
\text { Snakes } \\
\text { Drought (2035, } \\
\text { 2053, 2069) } \\
\text { Hurricane (2036) } \\
\text { Changes in wild } \\
\text { elephant behavior } \\
\text { Fire } \\
\text { Malaria epidemic } \\
\quad \text { (1932) }\end{array}$ & $\begin{array}{l}2 \text { people died due to floods } \\
\text { In } 2044 \text { Bikram Sambat. several households migrated } \\
\text { At the time of paddy cultivation, drought caused a loss in productivity } \\
\text { (1.5 man/Bigha or } 90 \text { kilograms/hectare }) \\
1 \text { person injured due to snake bite } \\
\text { Several people died due to malaria } \\
\text { Agricultural land washed away } \\
\text { Problems with mobility due to the destruction of a check dam }\end{array}$ \\
\hline Sangrumba & $\begin{array}{l}\text { Landslides (2021, } \\
\text { 2025, } 2067 \text { and } \\
\text { 2069) } \\
\text { Flood (2025) } \\
\text { Hurricane (2066) } \\
\text { Fire (2054) } \\
\text { Earthquake (1990 } \\
\text { and 2068) } \\
\end{array}$ & $\begin{array}{c}\text { Extinction of ducks } \\
16 \text { people died due to landslides and the loss of } 4 \text { means of } \\
\text { transportation } \\
\text { Loss in crop productivity } \\
1 \text { person died due to fire and } 1 \text { household experienced the loss of } \\
\text { property worth around } 7 \text { lakhs } \\
\text { Hurricanes affected } 44 \text { households and schools } \\
\text { Loss of } 11 \text { households due to an earthquake }\end{array}$ \\
\hline
\end{tabular}


One of the main reasons for the high level of vulnerability is the geology of the region itself. The soil is not very compact, and thus heavy rainfall and medium-size flooding can lead to serious erosion and landslides, with devastating impacts on farmland, houses, livestock, crops, roads, and consequently on human lives and livelihoods. Second, the population is growing, which is increasing the pressure on forests and farms. As a result, people are clearing more forests to till and grow crops, and agricultural land use practices are becoming more intense than ever in terms of cropping patterns and the use of chemical fertilizers and pesticides. Therefore, people are farming on infertile land due to infestations of disease/insects/pests, whereas some people are adopting new occupations and migrating from the area. However, migration is not a permanent solution to cope with these situations. Also, as a mitigation strategy, the people are adopting techniques such as indigenous varieties, fertilizers, water harvesting technology, conservation and the proper utilization of resources (plastic ponds, deep boring, pump sets, and sprinklers), resistant varieties and integrated pest management technology using contour farming. Also, Gavin construction and afforestation have been implemented to minimize the adverse effects of natural hazards.

\subsection{Major Causes of Climate Change and Disasters}

Between Bikram sambat 2002 and 2011, there were 4130 disasters recorded, resulting from natural hazards around the world, where 1,117,527 people perished and a minimum of US $\$ 1195$ billion was recorded in losses. More people and assets are located in high-risk areas due to changes in the environment such as rapid urbanization, human settlement, unsustainable development practices, ecosystem degradation, poverty as well as climatic variability and extremes, as shown in Table 3, which have led to an increase in both natural and man-made disaster risk at a rate that poses a threat to lives and development efforts.

Table 3. Major causes of the changing environment.

\begin{tabular}{cc}
\hline Changes in the Environment & Percent \\
\hline Deforestation & 94.3 \\
Human behavior & 89.7 \\
Uncontrolled population & 71.3 \\
Climate change & 54 \\
Urbanization & 29.7 \\
\hline
\end{tabular}

\subsection{Impact of Disasters}

The following outlines the major impacts found during the study of disaster-prone sites. Table 4 shows the general impacts of disasters. A total of $93.7 \%$ of the respondents stated that water sources are drying, $97.7 \%$ noted that there is a high infestation of insects that is affecting agriculture and productivity, $42.7 \%$ noted early maturity in crops and $66 \%$ claimed that there has been an invasion of new crops as the weather changes. Furthermore, the respondents claimed that there is a problem with diseases not only in human beings, but also in animals.

Table 4. General impact of disasters.

\begin{tabular}{cc}
\hline Impacts & Percent \\
\hline Infestation of insects & 97.7 \\
Drying of water resources & 93.7 \\
Decrease in productivity & 89.7 \\
Increase in crop disease & 72.7 \\
Increase in animal disease & 62.3 \\
Invasion of new crops & 66 \\
Early maturity & 42.7 \\
Flowering in forests & 20.3 \\
Disease in human beings & 36.7 \\
Increase in productivity & 8.3 \\
\hline
\end{tabular}


The general impacts of disasters can be discriminated in more detail as impacts related to agriculture, livestock and economic losses, leading to a decrease in productivity, vector diseases and loss of livelihoods, among others. As shown in Table 5 the high percentages of decrease in productivity in the three evaluated dimensions ranges between $83.3 \%$ and $95.6 \%$.

Table 5. Impact on agriculture, livestock, and the economy.

\begin{tabular}{cc}
\hline Impacts on Agriculture & Percent of Cases \\
\hline Decrease in productivity & 92.5 \\
Increase in insect infestation & 87.5 \\
Agricultural land washed away & 60 \\
\hline Impacts on Livestock & \\
Decrease in productivity & 83.30 \\
Loss of fodder and foraging & 77.80 \\
Reduce in productivity of livestock & 53.60 \\
Disease & 38.60 \\
Livestock washed away & 2.40 \\
\hline Impacts on Economic Resources & \\
Low productivity & 95.6 \\
Reduction in income & 88.2 \\
Disease & 32.1 \\
Starvation & 4.4 \\
\hline
\end{tabular}

\subsection{Effects on the Environment of These Disasters}

As shown in Table 6, most of the people stated that disasters affect the environmental conditions by different means, such as a decrease in surface water, which not only creates drought but also problems with drinking water, an increase in pollution, loss of biodiversity, and a loss of human/animal life due to diseases and insects.

Table 6. Disaster effects on the environment.

\begin{tabular}{cc}
\hline Effects on the Environment & Percent of Cases \\
\hline Decrease in surface water & 94.6 \\
Pollution & 74.2 \\
Loss in biodiversity & 50.3 \\
Loss of life & 6 \\
\hline
\end{tabular}

Indigenous knowledge and natural resource management skills also provide opportunities to manage disasters. This is because the management of natural resources is a significant aspect of disaster management. Various communities in Nepal have retained indigenous knowledge and skills in managing natural resources, particularly forests and water resources, which are the major factors in both managing and causing disasters. They have skills in harvesting trees and the protection of water resources. Currently, forest resources are being managed by communities of users. This system of management of natural resources facilitates the implementation of the disaster management system.

\subsection{Local Mitigation Methods}

To cope with this situation, people have developed early warning and monitoring systems through different local organizations, cooperatives and social media, alternative agriculture, such as poultry raising, mushroom cultivation, tunnel/greenhouse farming, short-duration crop cultivation (e.g., hybrid cultivation), cultivation of drought-tolerant crops, and crop varieties, e.g., taro, yam, millet, sathiya local variety of maize. As well as the formation of hamlet development institutes and a social network, the mobilization of youth to create awareness, exchange the information, and facilitate participatory decisions are the major techniques that the Ilam district is implementing to lessen the calamities. Methods for mitigation of landslides, floods and droughts are shown in Table 7. 
Table 7. Mitigation methods used by respondents.

\begin{tabular}{cc}
\hline Mitigation Methods for Landslides & Percent of Cases \\
\hline Afforestation & 97.7 \\
Contour farming & 78.9 \\
Awareness & 51.6 \\
Check basin & 48.4 \\
Change of housing location & 11.7 \\
Reconstruction of sheds & 3.1 \\
Loans for household activities & 3.1 \\
\hline Mitigation Methods for Floods & \\
Check basin & 92.9 \\
Awareness & 92 \\
Loan for household activities & 13.3 \\
Change of housing location & 7.1 \\
Reconstruction of sheds & 5.3 \\
\hline Mitigation Methods for Drought & 89.6 \\
Conservation and utilization of resources & 40.7 \\
Drought-resistant varieties & 8.6 \\
Construction of plastic ponds &
\end{tabular}

\subsection{Social Networks}

A social network is a social structure made up of a set of social actors, such as individuals or organizations, and a set of the dyadic ties between these actors. The social network perspective provides a set of methods for analyzing the structure of whole social entities, as well as a variety of theories explaining the patterns observed in these structures. The study of these structures uses social network analysis to identify local and global patterns, locate influential entities, and examine network dynamics. According to respondents, their major sources of the information are radio, TV, and also relatives, neighbors, and friends. Social media allows everyone to play the role of the journalist in sharing the events that are happening around them.

There are different sources of information - such as television, radio, friends, relatives and the neighbors - and the study showed that $97 \%$ of respondents obtained information from the radio, as it is the best and cheapest means to have at home. Although the district has many more organizations, non-organizations, institutions, and clubs that are working in the field of climate change and disaster, the study showed that only $30.7 \%$ of respondents received help from these sources after a disaster.

As shown in Table 8, respondents help each other in the case of a disaster by providing basic needs, such as clothes, shelter for living and food. Some help by providing loans and others by providing information to help cope with the disaster risks.

Table 8. Means by which respondents helped each other.

\begin{tabular}{cc}
\hline Means of Helping Others & Percent of Cases \\
\hline Helping hands & 77.4 \\
Information & 61.6 \\
Providing basic needs & 48.4 \\
Loans & 18.3 \\
\hline
\end{tabular}

\section{Conclusions and Recommendations}

The climate is changing, leading to different natural hazards and increases in life-threatening situations for humans and livelihoods. Usually natural disasters cannot be stopped still; the magnitude of disasters can be reduced if preventive measures be taken in due time for which pragmatic government policies and public awareness are of utmost importance [10].

Local people are using their indigenous knowledge and technology to cope with these disasters and reduce the risk of climate change. Some new interventions, such as rainwater harvesting for drinking and perennial agriculture, farming that conserves water and crop nutrients, the promotion of 
drought-tolerant crops (e.g., sweet potato and sorghum), seed multiplication and crop diversification and communal gardening can be implemented to improve sustainable livelihoods. Not only in Nepal, natural disasters happen almost all over the world all of a sudden causing heavy loss of human life, destruction of infrastructure and properties.

Vulnerability and resilience have a mutually dependent effect on communities coping with different situations. When one increases, the other decreases, meaning that strengthening people's resilience leads to better coping mechanisms and a reduction in vulnerability. The best possible outcome of decreasing people's dependence on outside resources and assistance is that it might lead to the better stability of the district.

\section{References}

1. Nepal Disaster Report, $2009 . \quad$ Available online: https://www.undp.org/content/dam/nepal/docs/reports/drm/UNDP_NP_Nepal\%20Disaster\%20Report\%2 02009_The\%20Hazardscape\%20and\%20Vulnerability.pdf_(accessed on 22/10/2013)

2. Natural Disaster Relief Act; His Majesty's Government of Nepal: Kathmandu, Nepal, 1982.

3. Disaster Management in Nepal-A Profile; His Majesty's Government of Nepal, Ministry of Home Affairs: Kathmandu, Nepal, 1994.

4. Turnbull M., Sterrett, C., Hilleboe A. Towards Resilience, A guide to Disaster risk reduction and climate change adaptation. Practical Action Publishing: Rugby, UK, 2013

5. Gautam, D. 'Floods and Need Assessment, a Sociological Study from Banke, Bardiya and Kailali of Mid and FarWestern Nepal', Lutheran World Federation, Nepal, in We Know What We Need: South Asian Women Speak out on Climate Change Adaptation, Action Aid/IDS; Action Aid International: Johannesburg, South Africa, 2007.

6. IPCC. Contribution of Working Group II to the Fourth Assessment Report of the Intergovernmental Panel on Climate Change, Summary for Policymaker; IPCC: Geneva, Switzerland, 2007.

7. IPCC. 2007: Climate Change 2007: Synthesis Report. Contribution of Working Groups I, II and III to the Fourth Assessment Report of the Intergovernmental Panel on Climate Change; Core Writing Team, Pachauri, R.K., Reisinger, A., Eds.; IPCC: Geneva, Switzerland, 2007; 104p.

8. UN/ISDR. Hyogo Frame for Action 2005-2015: Building the Resilience of Nations and Communities to Disasters. In Proceedings of the World Conference on Disaster Risk Reduction (www.unisdr.org), Kobe, Japan, 18-22 January 2005.

9. National Adaptation Programme of Action (NAPA); Ministry of Environment, Government of Nepal: Kathmandu, Nepal, September 2010.

10. Problems of Disaster Management in Nepal and Measures to Solve Them; A Report prepared by a Task Force; His Majesty's Government of Nepal, Ministry of Home Affairs: Kathmandu, Nepal, 1998.

(C) 2018 by the authors. Licensee MDPI, Basel, Switzerland. This article is an open access article distributed under the terms and conditions of the Creative Commons Attribution (CC BY) license (http://creativecommons.org/licenses/by/4.0/). 